\title{
Development of an innovative integrated curriculum for process improvements in a product development organisation
}

\author{
Kavian O. Cooke Ph.D ${ }^{1}$, Steve Fanon M.Sc ${ }^{2}$, and Felician Campean Ph.D ${ }^{1}$ \\ ${ }^{1}$ Faculty of Engineering and Informatics, University of Bradford, Richmond Road, BD71DP United \\ Kingdom, k.cooke1@ bradford.ac.uk, f.campean@bradford.ac.uk \\ ${ }^{2}$ Jaguar Land Rover, Banbury Road Gaydon, Lighthorne Heath, Warwick CV35 ORR United Kingdom, \\ sfannon@jaguarlandrover.com
}

\begin{abstract}
This paper explores a teaching methodology underpinned by the six-sigma framework, which was used to develop an academic programme between the University of Bradford and Business partner Jaguar Land Rover. The proposed methodology utilises a blended approach that integrates academic learning, through interactive classroom learning and workplacebased learning under the supervision of a Master Black Belt. Candidates within the programme develop skills in leadership, project and stakeholder management, and communication. The learning infrastructure includes peer support in which experienced learners use their acquired knowledge and understanding to support those at earlier stages. The result is an 'Eco-system' which develop self-sufficient networks and communities of capable engineers. Learning within the programme has triggered multiple research projects that contribute significantly to organisation knowledge, cost, and quality. Confirmation of candidate knowledge and learning is undertaken by the university using a curriculum aligned to SixSigma 'certification' standards.
\end{abstract}

Keywords: Engineering education, Innovative, Integrative, Constructivist learning.

\section{INTRODUCTION AND BACKGROUND}

Action-based blended learning is an approach to engineering education that combines an academic style delivery with a work place-based project under the supervision of an experienced practitioner. The field of engineering education continues to evolve rapidly with the development of various teaching methodologies that highlights the importance of pedagogical skills, learner/students' prior knowledge and the way in which that prior knowledge is harnessed and used as a part of the learning experience.

Learning itself is a process of acquiring new knowledge "through the transformation of experience" [1], and Kolb identifies that individuals have different preferred 'learning styles'. Kolb's model for 'experiential learning' (Fig. 1) characterises both learning styles, and a learning cycle for building knowledge and cognition, and is widely cited in the literature.

Digital Object Identifier (DOI):

http://dx.doi.org/10.18687/LACCEI2020.1.1.193

ISBN: 978-958-52071-4-1 ISSN: 2414-6390
The cycle has two axes, the 'Processing Continuum' describing an approach to a task, and the 'Perception Continuum', representing thinking and feeling, and at each end of these continua is a learning style. It is expected that individual learners will have a preferred learning style, but also that effective learning will be achieved through continuous loops of the learning cycle [1].

Hassan [2] presents a comprehensive assessment of learning theories for engineering education and concludes the need to combine multiple approaches for effective learning, and the importance of including assessment as a holistic part of the education process. Behaviourism, socio-cultural, and constructivism learning theories are all relevant to the modern Engineering education environment. Useful tactical approaches for Engineering learning can be derived from all of these theories, and of particular relevance for a work-based learning programme are Scaffolding [3], Problem-based learning, but also the use of feedback to learners on their learning journey [4].

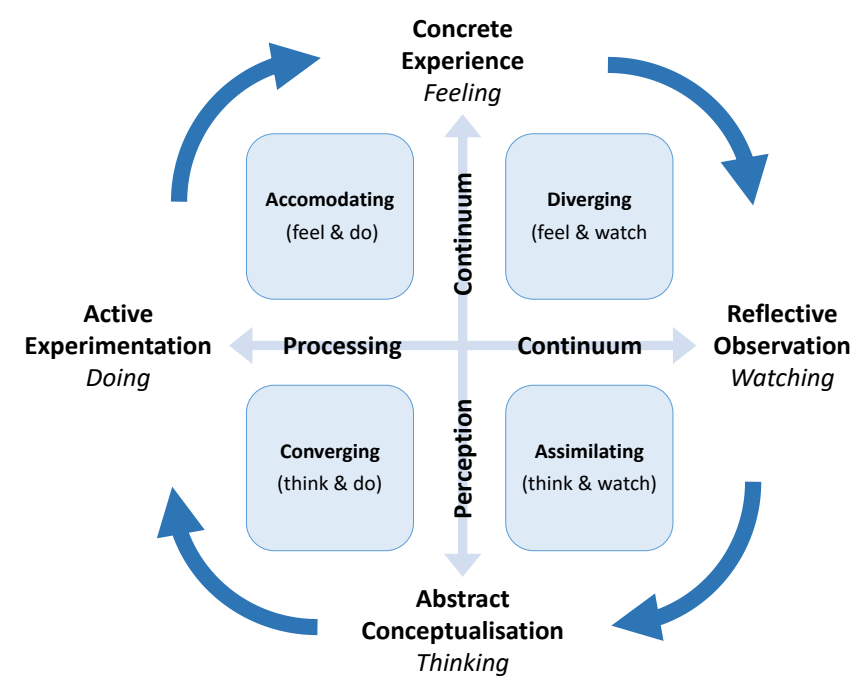

Fig. 1 - Kolb’s ‘Experiential Learning' Cycle [1].

Training is an important means of "building quality into people" by developing their competences [5], but also in

18 $^{\text {th }}$ LACCEI International Multi-Conference for Engineering, Education, and Technology: "Engineering, Integration, and Alliances for a Sustainable Development" "Hemispheric Cooperation for Competitiveness and Prosperity on a Knowledge-Based Economy", 27-31 July 2020, Virtual Edition. 
shaping their beliefs and values, which contribute to behaviours, and underlying organisational culture [6]. Prior to Six-Sigma, applied statistics training programmes within industry identified the importance and applications of statistical methods, but without providing the over-arching programme, project framework or support infrastructure [7]. This suggests the importance of building 'procedural' and 'metacognitive' knowledge and enabling the effective deployment of that knowledge [8].

Six Sigma is described as an approach to both CI and improved business performance [9]. Through the reduction of variation, Six Sigma focusses on continuous and breakthrough improvements [10]. The main thrust of Six Sigma is in the delivery of projects aligned to the priority strategic needs of the organisation. Those projects should have a measurable impact which can be sustained in the long-term by the organisation.

Beyond strategic alignment, project delivery, and tools, another significant difference with the Six Sigma approach is the development of an internal infrastructure within an organisation to support the deployment, development of staff and delivery of improvement projects [11]. Internal resources are important for the Six Sigma approach to survive, and the development of competences for the various roles in an organisation is vital to success or failure of the approach [12].

Some areas of 'Lean' literature focus heavily on the importance of 'learning by doing' [13], somewhat failing to recognise that learning away from the work environment is necessary to ensure that the right level of knowledge and cognition is being developed. Learning away from the workplace can also create 'psychological safety' in the learning environment - "a shared belief that (the team and environment) is safe for inter-personal risk taking", and this is known to be important to support effective learning behaviour [14]. The pressure for 'exploitative' learning or for immediate benefit - in the workplace environment can also compromise the learning behaviours of individuals and teams in contrast with 'explorative' learning [15]. At the same time, the workplace environment is where the benefits of learning need to be delivered, and can be an important place for later consolidation of learning, applying 'active experimentation' and developing 'concrete experience' [1].

Another important consideration for learning programmes in a workplace environment is the target audience being mature learners. Spigner-Littles and Anderson [16] present 'Constructivism' as an important learning approach for older learners, where the mature learner is encouraged to recognise what they already know and build new information into their existing cognitive structures. The constructivist theory suggests that learners need to find the subject relevant and linked to prior knowledge. In a collaborative learning environment and under the guidance of an instructor as a facilitator/moderator, interactive learning activities help the learner to construct a new understanding of the subject. In the constructivist approach, the learners themselves share responsibility for their learning, in collaboration with other learners, in some cases exercising their judgement on where and how the learning takes place and prioritisation of time. A 'Project Based Learning' (PBL) approach is another theory, which breaks the stereotype of lecture-based training in the workplace. With PBL, "Projects are the platform for students to achieve competences", again allowing students to own their own learning, guided by a facilitator who presents ideas, methods, and tools [17]. Typically, the projects are teambased, thus the students learn from other students, the project work, from their advisors, from practice, and from other reference material used. Learners will "find their way to knowledge and skill in a learning environment that encourages initiative and creativeness" [18]. PBL is particularly relevant for mature learners, as they will already have the basic team working skills required for the effectiveness of this method [19] and further enhancement of these skills are important for effective delivery of improvement projects in a work-based environment. It is clear that training is only one approach to deliver learning and develop competence, and a wide choice of alternative options are required in a successful modern engineering education programme.

There are at the same time, cultural and psychological barriers to individual learning within an organisation to consider according to Schein [6], which can be summarised as the following individual fears:-

- Loss of power or position... less power or status

- Temporary incompetence... not having mastered the new way

- Punishment for incompetence... if learning takes a long time

- Loss of personal identity... when organisational values change

- Loss of group membership... when culture changes

These fears potentially leading to change resistance, it is important to create psychological safety during learning and connect the new learning to survival needs. Schein goes on to propose counter-measures to these fears and resulting resistance to learning:

1. A compelling positive vision

2. Formal training

3. Involvement of the learner

4. Informal training of relevant "family" groups and teams 
5. Practice fields, coaches, and feedback

6. Positive role models

7. Support groups to share and discuss learning problems

8. Systems and structures consistent with the new way of thinking and working

As Jaguar Land Rover (The Business) emerged from the 2008 global recession in the hands of new owners, the organisation developed a corporate strategy framework in the form of a 'Vision Triangle', which provided clear direction on the attributes of Jaguar Land Rover business going forward in the second decade of the 21 st century. This strategic vision made it clear that the technical functions of the business would need to be at the heart of this work through a focus on products, and therefore be equipped with the required skills and competencies. The development of the Technical Accreditation Scheme' (TAS) in partnership with UK universities provides tailored post-graduate learning, with the strapline "The Best Courses from the Best Sources". The programme gives technical staff the opportunity to achieve post-graduate academic awards by pooling together credits awarded by University partners. Between 2010 and 2017, a significant proportion of Jaguar Land Rover technical staff participated in more than 6000 TAS learning modules.

This paper outlines a learning framework that delivers an academic programme within a product development environment. The programme is underpinned by the sixsigma methodology as a way of delivering engineering education to post experienced students in the work environment.

\section{DESIGN AND DEVELOPMENT OF THE PROGRAMME}

The "Engineering and Process Excellence" (E\&PE) programme developed by the University of Bradford was designed to fit within the Jaguar Land Rover TAS programme to meet the needs of the company that were previously addressed by "Six Sigma" training, and further enhance this by combining the personal incentives and academic rigour associated with university led post-graduate learning. The objectives considered during the process for developing the learning programme included; (1) Identifying the key learning outcomes for the company, which were shaped by the previous six-sigma training programme; (2) Develop a modular framework within which both the academic award and the "Belt" certification were accommodated. (3) Develop learning materials with real-life examples from onsite engineering problems encountered by Jaguar Land Rover engineering teams. Finally, (4) establish a process of recognising prior learning within the programme. These objectives were achieved by:
- Developing a modular Learning programme taking the best of existing interactive classroom training, and integrated academic learning.

- Create a progressive development journey - from 'Green Belt' through 'Black Belt' competence levels and beyond this to 'Black Belt Coach' level

- Align the programme to Six-Sigma 'Belt' Certification levels recognised internally

- Develop workplace based 'Project' delivery as the basis for academic assessment

- Create modular 'Black Belt' content... as an integrated programme, and modules individually accessible for 'stand-alone' study

- Created multiple entry points - options to accredit prior learning outside this programme

- Create multiple exit points - dependent upon individual and workplace objectives

- Regular programme cycles of learning, so that classes are kept small.

Fig. 2 shows a schematic outlining the structure of the programme starting with the Green Belt development, which challenges the candidates to interact with the learning material covered in the course. The Green Belt stage of the programme culminates with a research project from which results are presented at the Jaguar Land Rover Green Belt Conference. Stage 2 takes the delegates through the Black Belt development programme, which includes six modules each of which culminates with a research project. Delegates who are interested in progressing further into engineering and process excellence have the opportunity to complete three additional TAS modules and an MSc project. These modules can be taken from any of the modules delivered by collaborating universities.

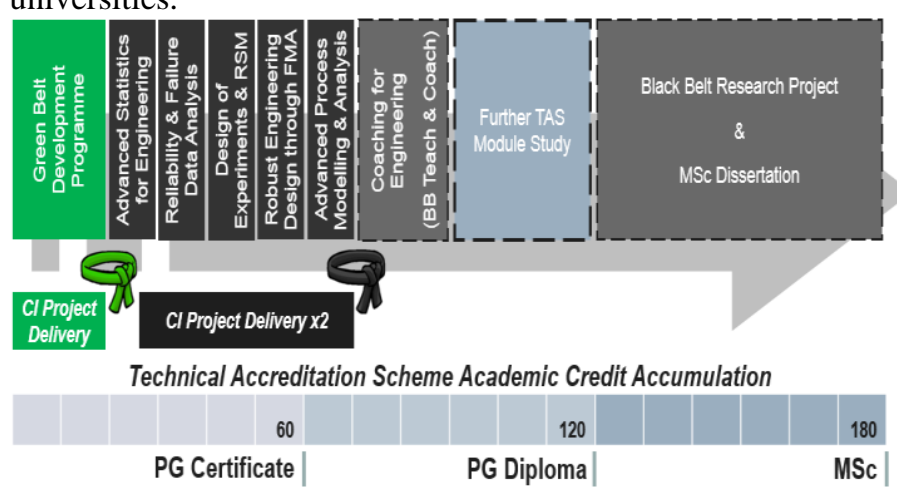

Fig. 2 Engineering \& process excellence programme.

\section{AN INTEGRATIVE TEACHING AND LEARNING FRAMEWORK}

The programme was designed in a modular short course format with formal classroom-based sessions rooted in the principles of constructivist learning in which the theoretical principles are explained in an engineering context [1][2][3]. These principles are reinforced by real-world engineering problems and class activities such as tutorials and case studies 
are designed to enhance understanding and skills development.

Approximately fifty percent $(50 \%)$ of the class time is spent teaching from learning materials, which are often directly linked to ongoing research. The other fifty percent $(50 \%)$ of the session is spent completing; tutorials, case studies, and exercise. The learning framework also takes into consideration the wide experience of successful Six-Sigma project delivered within the organisation using the DMAIC (Define, Measure, Analyse, Improve and Control) improvement framework, these projects were typically focussed on addressing the following:

- Product quality issues identified by external customers

- Product quality issues identified internally, including manufacturing 'First Time Through' and quality audit concerns

The programme was designed to ensure that the scope of potential improvement projects could be extended further within the organisation. Examples of this structure can be seen in the 'Failure-Mode Avoidance' (FMA) module. The knowledge of engineering robustness methods and tools led to a logical extension in the improvement project scope to include Systems Engineering design \& Failure-mode Avoidance projects and DMAIC projects which focus on definition, improvement, and evolution of Engineering Standards, including improvement to detection methods and design rules.

The joint collaborative Jaguar Land Rover \& University E\&PE leadership team emphasised the importance of projects scoped to deliver business benefits throughout the product creation, manufacturing, and service life cycle. This resulted in projects being scoped by candidates, which would improve the engineering process and develop new technical capabilities required to enable a more robust process

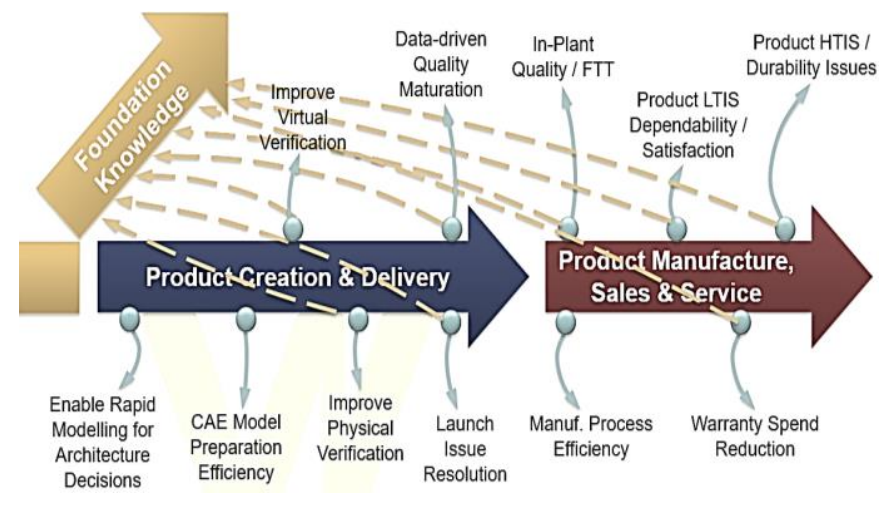

Fig. 3 Scoping of work-based improvement projects within the E\&PE Programme \& their benefits

Fig. 3 shows the origin of various workplace-based improvement projects delivered by learners within the E\&PE programme. Several different new-model programmes are delivered through the product creation \& delivery value- stream each year and many more product lines are live within the entire value stream and in-service with customers. This figure also describes how underlying learning within these projects can contribute to the collective organisation knowledge through updates to documented methods, standards, design rules, etc.

\section{A. Peer assisted learning}

A key component of the E\&PE programme is the development of a supporting 'ecosystem' that helps to develop future learners within the programme and ensures their ongoing application of high-level capabilities in the workplace. A learner-led "teach-back" session is held at the end of many modules providing a forum for rich discussion and early consolidation of learning in the classroom environment. As the post-training projects progress "project clinics" are organised with groups to encourage peer input, peer networking, and coaching.

Whilst the 'Belt' structure of Six Sigma provides some basis for an infrastructure of improvement capability. It was necessary to develop a formal support network and clear contracting with individuals on the role that they needed to play in enabling this learning 'ecosystem'. This involved both subtle and more overt tactics developed by the leaders of the E\&PE programme. New learners developing at the 'Green Belt' level were required to identify a 'Black Belt' in their local area who would provide coaching and occasional technical support. The 'Black Belt Coach' would be asked to sign-up to the developing 'Belts' pre-course candidate 'Charter', as a pre-requisite to course entry. The 'Black Belts' were provided with internally delivered leadership training, which enhanced their leadership skills and made clear their role in supporting the Six Sigma infrastructure of the organisation, which include coaching and support for other learners.

The E\&PE programme was extended to include a 'Coaching for Engineering' learning module in order to develop future improvement leaders and highly competent internal teachers and coaches for improvement methods in the business. This module is co-delivered by University and workplace 'Master Black Belts' in partnership and enabled learners to develop the presentation and teaching skills required for a commanding presence in presentation scenarios and deliver effective classroom teaching, as well as providing coaching skills. Completion of this learning module required 'Black Belt Coached' candidates to deliver short classroom training sessions to 'Green Belt' classes, and to coach several 'Green Belts' to successful project completion.

\section{B. ASSESSMENT}

Assessment of the students' progress through the programme is accomplished by a technical report on a workplace based "applied" research projects geared towards solving actual engineering problems. This is accomplished by applying the 
technical learning within a research method framework, which ensures;

- $\quad$ End-to-end workplace-based improvement projects within a DMAIC framework

- Informal research \& application of methods \& tools within an improvement project

- Dissertation projects are formal research

- Reflection on personal learning is a fundamental part of the assessment

- Descriptive feedback on assessment

\section{ACCREDITATION OF THE PROGRAMME}

The Technical accreditation scheme was established within a holistic model for the development of the technical capabilities required by the organisation Fig.4 shows the different entry points of technical employees into the programme depending on their respective learning and development needs. The E\&PE programme delivers workbased learning for employees already established in technical roles within the organisation, and those progressing within the Graduate development programme towards an MSc in process excellence which is accredited by the Institute of Mechanical Engineers (IMechE). The learning academy framework covers the full breadth of technical learning within the organisation young Apprentices to Doctorate level as shown in Fig. 4.

The success of the E\&PE programme is evidenced by the impact of the graduates and projects that are completed. The quality and innovativeness of the E\&PE programme was further recognised by SEMTA Skills Awards 2017 'Highly Commended' in the 'Skills Innovation of the Year' category.

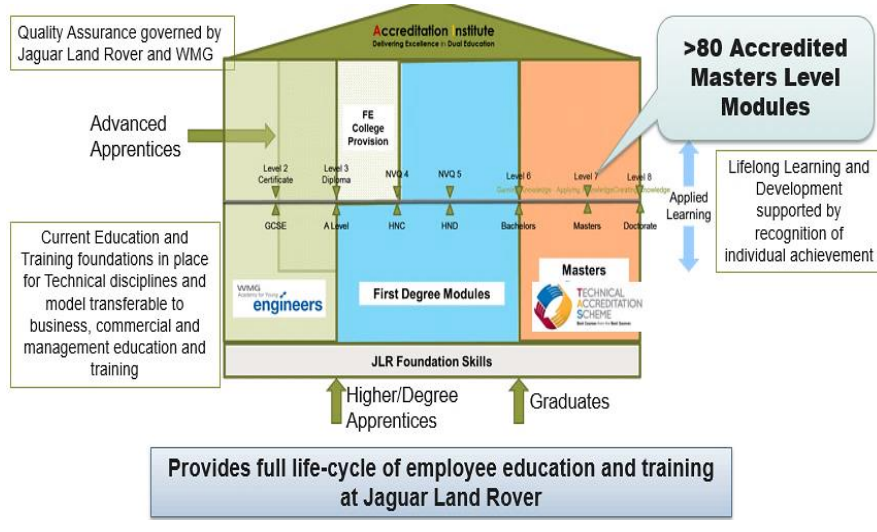

Fig. 4 technical leaning framework model

\section{IMPACT ON THE BUSINESS PARTNER}

The improvement projects delivered within the E\&PE programme typically contribute on average of $£ 50-100 \mathrm{k}$ of direct and indirect business benefit. All of the improvement projects delivered by candidates within this programme are 'customer driven' and business 'scorecard' aligned, typically with a direct linkage to the company's external customers. Typical projects include:

- Product Quality Improvement- these types of projects are driven by customer satisfaction survey data, warranty data, internal quality audit data, etc.

- Product engineering process improvement involves the capture of customers' product requirements, more robust and/or faster product design optimisation/verification (internal \& external customer impact)

- Engineering capability development needs that remove 'bottlenecks' and enables the faster delivery of products

Beyond the benefits that can be calculated financially, there are significant additional business benefits from these projects relating to:

- Foundation knowledge updates including; technical standards, design rules, processes, DFMEA improvements, design verification method robustness improvements

- Capability development projects that produce new technical tools, methods, processes which contribute to cost, quality, or delivery time improvements within 'Product Engineering', or 'Manufacturing, Sales \& Service' value-streams

- Certification \& academic accreditation of learnersthe programme currently has 1530 candidates certified at 'Green Belt' level, 120 candidates working towards $\mathrm{BB}$ certification (14 certifications to date), and 6 candidates registered to complete MSc award (28 MSc, 17 PgD awards to date)

- Identification of previously unseen opportunities for improvement and future research needs - extending from tactical process \& quality actions to strategic project delivery. These needs regularly drive further projects delivered within the learning programme.

\section{FEEDBACK FROM THE LEARNER}

A survey conducted among pass students at all levels (Green Belt, Black Belt, and MSc) one year after completion showed that over $90 \%$ of interviewees felt the programme had significantly positive impact on; their 'ability to solve unfamiliar problems in the workplace', their 'enthusiasm for future learning', and 'perceived benefit to their career' (Fig. $5(\mathrm{C})$ ). Black Belt candidates within the programme indicate that they developed skills for leadership, project and stakeholder management, and communication skills. The learning support infrastructure makes use of the acquired knowledge and understanding of more experienced learners to support those at earlier stages. Improvement project delivery for Jaguar Land Rover is the most important currency within this programme, and projects are robustly documented in 
summary form, and within technical reports for the organisation and individual learning. Project success is shared and celebrated throughout the organisation.

Eighty-five percent $(85 \%)$ of the past student interview indicated that the practical activities completed during the training helped them to learn (see Fig. 5 (A)). Another ninetyseven percent $(97 \%)$ of the respondents agreed that their workplace-based project helped to further develop the skills learned on the course (see Fig. 5 (B). Finally, eighty-eighty percent $(88 \%)$ of respondents agree that the course has stimulated my interest in the field of study Fig. 5 (D).
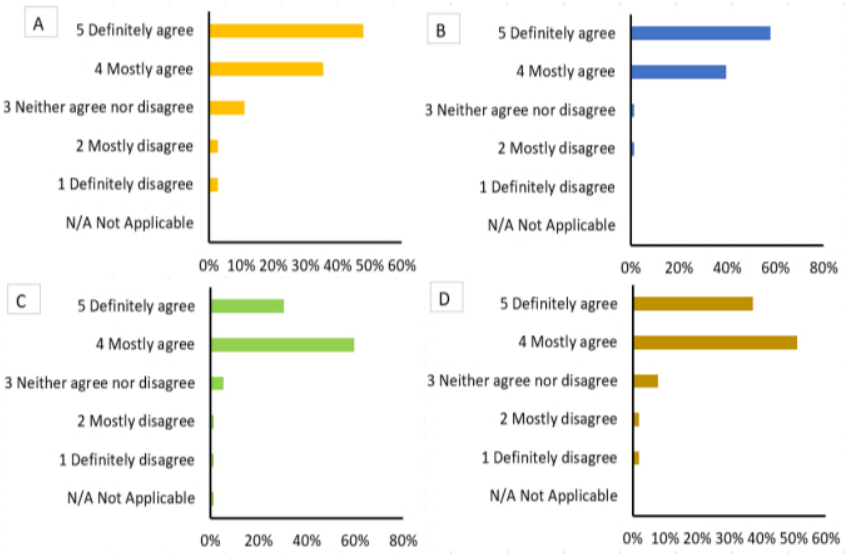

Fig. 5: show the result of a survey conducted among the programme past students (A) the practical activities completed during the training helped them to learn (B) that the project helped to further develop the skills learned on the course (C) positive impact on; their 'ability to solve unfamiliar problems in the workplace' (D) Question 4 the course has stimulated my interest in the field of study.

\section{CONCLUSIONS}

This article outlines a learning framework used to deliver an academic programme within a product development workplace environment, and in collaboration with a wider post-graduate accredited learning programme and in partnership with the organisations own technical leaders. The programme is underpinned by the six-sigma methodology as an approach to product and process improvement and the improvement project delivery focus that this brings.

The success of the partnership between the University of Bradford and Jaguar Land Rover has included the completion of hundreds of research projects resulting in significant savings for the company. One significant Jaguar Land Rover funded University led research project to develop an "Integrated Systems Engineering and Failure-Mode Avoidance framework" for deployment within the business was instigated as a direct result of the learning programme. Additionally, multiple MSc research projects have been delivered that contribute significantly to the organisation knowledge, cost, and quality.

This programme has significantly grown the community of Six-Sigma practitioners at Jaguar Land Rover at the 'Green
Belt' and 'Black Belt' levels. The programme continues to engage these individuals as a community to support each other, and others across the wider business who may benefit from the use of these methods \& tools. Jaguar Land Rover now has a sizeable self-supporting community of practitioners using these methods and tools in the workplace, and supporting others in their learning.

\section{REFERENCES}

[1] D. A. Kolb, Experiential Learning: Experience as the Source of Learning and Development, 2nd ed., Pearson Education, Inc., 2015.

[2] O. A. B. Hassan, "Learning theories and assessment methodologies - an engineering educational perspective," European Journal of Engineering Education, vol. 36, no. 4, pp. 327-339, 2011.

[3] B. Rosenshine and C. Meister, "The use of scaffolds for teaching higher-level cognitive strategies," Educational Leadership, vol. 49, no. 7, pp. 26-33, 1992.

[4] J. Hattie and H. Timperley, "The Power of Feedback," Review of Educational Research, vol. 77, no. 1, pp. 81112, 2007.

[5] M. Imai, Kaizen, New York: Random House Inc., 1986.

[6] E. H. Schein, Organizational Culture and Leadership, 4th ed., San Fransisco: John Wiley \& Sons, In., 2010.

[7] M. Harry and R. Schroeder, Six Sigma: The Breakthrough Management Strategy Revolutionizing the World's Top Corporations, New York: Doubleday, 2000 .

[8] D. R. Krathwohl, "A Revision of Bloom's Taxonomy: An Overview," Theory Into Practice, vol. 41, no. 4, pp. 212-218, 2002.

[9] British Standards Institution, BS ISO 13053-1:2011 Quantitative methods in process improvement - Six Sigma - Part 1: DMAIC methodology, British Standards Institution, 2011.

[10] R. Andersson, H. Eriksson, and H. Torstensson, "Similarities and differences between TQM, six sigma and lean," The TQM Magazine, vol. 18, no. 3, pp. 282296, 2006.

[11] T. Bendell, "A review and comparioson of six sigma and the lean organisations," The TQM Magazine, vol. 18, no. 3, pp. 255-262, 2006. 
[12] G. Eckes, Making Six Sigma Last: Managing the Balance Between Cultural and Technical Change, John Wiley \& Sons Inc., 2001.

[13] R. Martichenko, R. Pearce, W. Miller, M. Callahan, T. Vinas, and M. Lasalla, People: A leader's day-to-day guide to building, managing and sustaining lean organisations: People, LeanCor, 2014.

[14] A. Edmondson, "Psychological Safety and Learning Behaviour in Work Teams," Asministrative Science Quarterly, vol. 44, pp. 350-383, 1999.

[15] A. S. Choo, K. W. Linderman, and R. G. Schroeder, "Method and Psychological Effects on Learning Behaviours and Knowledge Creation in Quality Improvement Projects," Management Science, vol. 53, no. 3, pp. 437-450, 2007.
[16] D. Spigner-Littles and C. E. Anderson, "Constructivism: A Paradigm for Older Learners," Educational Gerontology, vol. 25, pp. 203-209, 1999.

[17] K. Edström and A. Kolmos, "PBL and CDIO: complementary models for engineering education development," European Journal of Engineering Education, vol. 39, pp. 539-555, 2014.

[18] R. J. Lenschow, "From Teaching to Learning: A Paradigm Shift in Engineering Education and Lifelong Learning," European Journal of Engineering Education, vol. 23, no. 2, pp. 155-161, 1998.

[19] M. Peterson, "Skills to Enhance Problem-Based Learning," Medical Education Online, 1997. 